\title{
Robot-aided therapy for upper limbs in patients with stroke-related lesions. Brief report of a clinical experience
}

\author{
Federica Bovolenta ${ }^{1 *}$, Patrizio Sale ${ }^{2 \dagger}$, Valentina Dall'Armi ${ }^{3}$, Pierina Clerici ${ }^{1}$ and Marco Franceschini ${ }^{2}$
}

\begin{abstract}
This study was aimed at verifying the improvement on the motor impairment and functionality in 19 patients with chronic hemiparesis after stroke treated with a robot-aided rehabilitation protocol using the ReoGo ${ }^{\mathrm{TM}}$ system (Motorika Medical Ltd, Israel), and at evaluating the persistence of the effects after 1 month. The study also focused on the actual possibility of administering the robot-aided therapy with the ReoGoTM for the upper limbs and on the patients' degree of acceptance and compliance with the treatment. Subjects underwent an assessment prior to the start of the rehabilitation project (T-1), one at the start (T0), one at the end of the treatment (T1) and one after one month from the end of the treatment (T2). The following tests were administered: (i) Fugl-Meyer (FM) upper limb; Ashworth scale (AS); Functional Independence Measure (FIM $\left.{ }^{\mathrm{TM}}\right)$ (T-1 - T2); (ii) strength evaluation; Visual Analogue Scale (VAS) for pain; Frenchay Arm test (FAT); Box and Block test (BBT); Timed Up and Go (TUG) test (TO - T2). Additionally, the Euro-QoL questionnaire and a VAS for the treatment satisfaction were administered to the subjects. Non-statistical difference of scores at T-1 and T0 on almost the entire battery of tasks suggested a stable patients' performance prior to the start of the rehabilitation. With the exception of the Medical Research Council (MRC) and the AS sub-scales measuring -as appropriate- strength and spasticity of the shoulder, triceps and wrist, all scores showed a significant increase between T0 and T1. The improvement on the pain could not be proved significant $(p=0.10)$. A significant increase between T0 and T2 was found for all assessment scores, with the exception of the MRC for external shoulder rotators $(p=0.05)$ and of the AS for shoulder $(p=0.32)$ and wrist $(p=0.08)$. Substantial stability was observed between T1 and T2. Patients were capable of completing the treatment and showed good participant satisfaction. This pilot study led to the finding of a clinical improvement and excellent patients compliance. It is possible that the learning process experienced by the patients was robot-dependent, especially in consideration of the general maintenance of the achievements observed on all activities.
\end{abstract}

Stroke is currently the most important cause of disability in industrialized countries; it is the main cause of functional impairment of the upper limbs, with important effects on participation to activities of daily living [1]. The upper limbs remain non-functional at 6 months post stroke in $30 \%-66 \%$ of cases, while only $5 \%-20 \%$ of the patients fully recover upper limbs functionality [2]. In the last 10 years rehabilitative therapeutic interventions have been developed to provide the best possible treatment both in acute and chronic phases. In this context, research showed that an efficient treatment must be intensive and

\footnotetext{
* Correspondence: federica.bovolenta@libero.it

† Contributed equally

${ }^{1}$ Medicine Rehabilitation NOCSAE Hospital AUSL of Modena, Modena, Italy Full list of author information is available at the end of the article
}

specific [3], repetitive, functional and motivating for the individual $[4,5]$ in order to allow for a continuous progression in the process of learning, acquisition and generalization [6,7]. The development of robot-aided tools for neurological rehabilitation is a very stimulating prospective when considering their highly rehabilitative potentials [8-10]. The objective of this study is to verify the improvement on the motor impairment and functionality after a robot-aided rehabilitation treatment with the ReoGo ${ }^{\mathrm{TM}}$ system and the persistence of the effects after 1 month. A focus will also be towards the actual possibility of administering the robot-aided therapy for the upper limbs with the ReoGo ${ }^{\mathrm{TM}}$ system and on the patients' degree of acceptance and compliance with the treatment. Subjects with stroke (chronic hemiparesis) and with the following
C Biomed Central

(c) 2011 Bovolenta et al; licensee BioMed Central Ltd. This is an Open Access article distributed under the terms of the Creative Commons Attribution License (http://creativecommons.org/licenses/by/2.0), which permits unrestricted use, distribution, and reproduction in any medium, provided the original work is properly cited. 
inclusion criteria were prospectively recruited into this "before-after" study: (a) first acute event of cerebrovascular stroke; (b) unsuccessful conclusion of a previous rehabilitation program (with no evident improvement of motility recovery); (c) discontinuation from any upper limb rehabilitation treatment for at least 1 month prior to the first visit. The following subjects were not included in the study: (a) patients with severe cognitive, linguistic or perceptive impairment (Mini Mental State Examination (MMSE) < 24); (b) patients who refused consent to the study; (c) patients who interrupted the robotic treatment for more than 3 days. If the treatment was interrupted for less than 3 days, all missed sessions were recovered. All recruited patients signed an informed consent. Each patient underwent a treatment cycle using the ReoGo ${ }^{\mathrm{TM}}$ system. The treatment consisted of a total of 20 sessions lasting 45 minutes each, 5 days a week, for a total period of 4 weeks; the rehabilitative protocol designed by us consisted of exercises aimed at improving both movement type (i.e., the joints involved, with a proximal-distal progression) and mode of execution of the movement itself, with progression from passive movement to free movement. Forearm support was used during treatment. Specific tasks are described in Table S1, Additional file 1.

The first visit took place 1 month prior to the start of the treatment $(\mathrm{T}-1)$. Following visit were scheduled: immediately before the start of the treatment (T0), immediately after the end of the treatment period (T1), and after 1 month (T2) during which period patients underwent no specific rehabilitation for the upper limb. The assessment tasks were: Fugl-Meyer (FM) for upper limb with its subtest: Motor function, Sensation, Passive Joint Motion, Joint Pain. [Lindmark, Hamrin 1988) [11,12]; Strength evaluation of 10 muscles, according to the Medical Research Council (MRC) criteria [13]; Ashworth (AS) elbow, wrist and shoulder sub-scales for spasticity [14]; Visual Analogue Scale (VAS) for upper limb pain; Frenchay Arm test (FAT) [15]; Box and Block test (BBT) [16]; Functional Independence Measure $\left(\right.$ FIM $\left.^{\mathrm{TM}}\right)$ motor sub-score $[17,18]$. In addition, subjects underwent a comprehensive evaluation using the Timed Up and Go (TUG) test [19]. Lastly, the Euro-QoL questionnaire for the quality of life $[20,21]$ and a VAS for treatment satisfaction were also administered to the subjects. The evaluations timeline is detailed in table 1 .

Specific aims of this study were: (i) to verify that subjects' performance was stable prior to the start of the robotic treatment. This was done by comparing the performance at $\mathrm{T}-1$ and $\mathrm{T} 0$ with regards to the FM, FIM ${ }^{\mathrm{TM}}$ and AS; (ii) to detect the improvement on subject's clinical status and its maintenance at 1 month after the completion of the rehabilitation program. This was done by comparing the change in performance on all tests from $\mathrm{T} 0$ to $\mathrm{T} 1$ and $\mathrm{T} 2$ and from $\mathrm{T} 1$ to $\mathrm{T} 2$. The Wilcoxon test
Table 1 Timeline of the evaluations performed on all patients during the study period

\begin{tabular}{lclll}
\hline Tests & T-1 & T0 & T1 & T2 \\
\hline Fugl-Meyer motor function & $X$ & $X$ & $X$ & $X$ \\
MRC* & - & $X$ & $X$ & $X$ \\
Ashworth Scale & $X$ & $X$ & $X$ & $X$ \\
Visual Analogue Scale pain & - & $X$ & $X$ & $X$ \\
Frenchay Arm Test & - & $X$ & $X$ & $X$ \\
Box \& Block Test & - & $X$ & $X$ & $X$ \\
FIM ${ }^{\text {TM }}$ motor & $X$ & $X$ & $X$ & $X$ \\
Time Up and Go Test & - & $X$ & $X$ & $X$ \\
EURO-QoL* & - & $X$ & - & $X$ \\
Visual Analogue Scale satisfaction & - & - & $X$ & - \\
\hline
\end{tabular}

*MRC: strength evaluation of 10 muscles, according to the Medical. Research Council (MRC) criteria; EURO-QoL.

questionnaire on quality of life perception.

for paired data was applied to perform all time comparisons. The critical limit for significance was set at $\mathrm{p}<$ 0.05 . The statistical software STATA/SE Release 10 was used to carry out all statistical evaluations.

Nineteen subjects were included in the study, 13 (68.42\%) were males and 6 (31.58\%) females; 7 individuals $(36.84 \%)$ presented with left hemiparesis and 12 (63.16\%) with right hemiparesis. The sample average age was $55.74 \pm 12.60$ years, with a range of $26-71$; the average time elapsed since the acute event was $57.37 \pm$ 92.37 months, with a range of 8-295 months. Table 2 summarizes descriptive, clinical and psychological sample information. The follow-up visit (T2) could not be carried out on 3 patients because of difficulties encountered by their relatives in reaching the hospital.

Stability in the patients' performance prior to the start of the rehabilitative treatment, supported by the nonstatistical difference of scores at T-1 and T0 for all tasks, with the exclusion of the motor $\operatorname{FIM}^{\mathrm{TM}}(\mathrm{p}=0.01)$, was observed.

The improvement observed in the patients' performance from $\mathrm{T} 0$ to $\mathrm{T} 1$ reached statistical significance for the FM upper limb $(p<0.01)$ sub-scores, for the AS elbow sub-scale $(\mathrm{p}<0.01)$, for the motor FIM $^{\mathrm{TM}}(\mathrm{p}<$ 0.01 ), for all muscles' strength according to the MRC criteria -with the exception of the external rotators of the shoulder $(\mathrm{p}=0.18)$, triceps $(\mathrm{p}=0.06)$, wrist flexors $(\mathrm{p}=$ $0.13)$ and extensors $(\mathrm{p}=0.08)$-, for the BBT $(\mathrm{p}<0.01)$, for the TUG test $(\mathrm{p}=0.01)$, and for the FAT $(\mathrm{p}<0.01)$.

Similarly, statistical evidence for an improvement from T0 to T2 was found for the FM upper limb ( $<<0.01)$, for the AS elbow sub-scale ( $p=0.01)$, for the motor FIM $^{\mathrm{TM}}(\mathrm{p}<0.01)$, for the VAS pain $(\mathrm{p}<0.01)$, for all muscles' strength -with the exception of the external rotators of the shoulder $(\mathrm{p}=0.05)$-, for the BBT $(\mathrm{p}=$ $0.01)$, for the FAT $(\mathrm{p}<0.01)$ and for the TUG test ( $\mathrm{p}=$ 0.02 ). Statistical evidence in favor of a progressive 
Table 2 Demographic, clinical and psychological sample

\begin{tabular}{|c|c|c|c|c|}
\hline & & $\mathrm{N}$ & $\%$ & Mean \pm Std.Dev \\
\hline Time since Stroke & & 19 & & $57.37 \pm 92.37$ \\
\hline Age & & 19 & & $55.74 \pm 12.60$ \\
\hline \multirow[t]{2}{*}{ Gender } & Males & 13 & 68.42 & \\
\hline & Females & 6 & 31.58 & \\
\hline \multirow[t]{2}{*}{ Affected Side } & Left & 7 & 36.84 & \\
\hline & Right & 12 & 63.16 & \\
\hline \multirow[t]{3}{*}{ Disease Severity } & Mild & 9 & 47.37 & \\
\hline & Moderate & 9 & 47.37 & \\
\hline & Severe & 1 & 5.26 & \\
\hline \multicolumn{5}{|l|}{ EURO-QOL } \\
\hline \multirow[t]{3}{*}{ МOB } & Yes & 3 & 15.79 & \\
\hline & No & 15 & 78.95 & \\
\hline & Unknown & 1 & 5.26 & \\
\hline \multirow[t]{3}{*}{$\mathrm{CP}$} & Yes & 10 & 52.63 & \\
\hline & No & 7 & 36.84 & \\
\hline & Unknown & 2 & 10.53 & \\
\hline \multirow[t]{3}{*}{$A U$} & Yes & 3 & 15.79 & \\
\hline & No & 15 & 78.95 & \\
\hline & Unknown & 1 & 5.26 & \\
\hline \multirow[t]{3}{*}{ DD } & Yes & 4 & 21.05 & \\
\hline & No & 14 & 73.69 & \\
\hline & Unknown & 1 & 5.26 & \\
\hline \multirow[t]{3}{*}{$A D$} & Yes & 8 & 42.11 & \\
\hline & No & 10 & 52.63 & \\
\hline & Unknown & 1 & 5.26 & \\
\hline
\end{tabular}

improvement from $\mathrm{T} 1$ to $\mathrm{T} 2$ emerged for the motor $\operatorname{FIM}^{\mathrm{TM}}(\mathrm{p}=0.01)$ and the VAS $(\mathrm{p}=0.02)$. The perception of the quality of life, as measured by the Euro-QoL, did not show statistically significant variations over time; the VAS for patients' treatment satisfaction had an average score of $98.68 \pm 4.02$. Table 3 summarizes the sample performance over time at all clinical tests.

The study showed a positive evolution of the limitation of activity and functionality for all subjects.

The sample had a baseline FM in line with other studies (Table 3) $[10,22,23]$ and so was the increase in FM score (Lindmark and Hamrin) [10,22,23].

All subjects showed excellent compliance and remarkable satisfaction, highlighted by the results of the VAS rating and the absence of dropouts associated to intolerance to treatment. The increase in the motor FIM ${ }^{\mathrm{TM}}$ and the decrease on the VAS for the pain might be due to different strategies developed by the patients for compensating their motor deficits. This data is in accordance with Lauretani [2010] who observed a functional recovery after a rehabilitation treatment in patients discharged to home [24]. The statistically significant increase between $\mathrm{T} 0$ and $\mathrm{T} 2$ shows how the improvement observed immediately after completion of the rehabilitative protocol was maintained over time, even though the sample under examination included subjects in a stable disease stage. Our results are in accordance with those of Bosecker 2010, who studied 111 individuals with chronic impairment caused by stroke and trained with a robot [25]. Such a robot-guided treatment must be task-oriented, functional and motivating for the patient $[4,5,23]$, and therefore capable of determining a process of learning, acquisition and generalization [6,7]. The use-dependent robot-aided instruments (intensive and repetitive treatment) may favor functional reorganization phenomena, typical of neuronal plasticity $[3,26]$. Our experience is also in line with studies $[6,27]$ that confirm how this type of treatment does not negatively affect spasticity: in our sample, the elbow AS score was reduced, while no change, nor an increase in spasticity, was detected for the other joints [28]. The positive effect observed on the quality and speed of the walking performance, assessed through TUG both at T1 and T2, is also interesting. This data conforms with Esquinazi paper [29]. The results obtained from our study suggest that a motor and functional recovery takes place and can be interpreted as a possible result of the process of adaptation. In addition, it was also possible to observe a motor learning and generalization process, confirmed by the baseline improvements observed at $\mathrm{T} 1$ and maintained until 1 month after (T2), an indication of the fact that patients were not in a spontaneous recovery stage.

Further research with higher statistical power is necessary. The enrolment of a control group would provide a term of comparison for the identification of the timedependent effects, thus addressing the question of whether improvements are therapy-dependent or effectively acquired. Eventual relationships between clinical outcome and potentially influential factors should be explored. Stronger evidence would be beneficial when coming to make the decision of using robotic devices as an integral part of the rehabilitation team activities, within a rehabilitation project designed accordingly to the specifications and objective requirements of each patient. In this context, subjects at different disease stages (i.e. patients in the acute and sub-acute phases) should be considered in future research. Indeed, while there are several studies with various robotic systems for the upper limb in acute/sub-acute stroke patients [30-32], only one study with ReoGo ${ }^{\mathrm{TM}}$ system in the sub-acute phase [33] has been carried out so far. The implementation of different protocols according to the severity of the impairment should also be considered.

The results obtained in terms of recovery in functionality and the restriction of participation, as well as in patients' compliance and operator satisfaction, are encouraging in spite of the limitations of this study. The significant improvements found from the baseline measurements to the end of the treatment may be an 
Table 3 Performance at the clinical assessment tasks

\begin{tabular}{|c|c|c|c|c|c|c|c|c|c|c|c|c|c|}
\hline & & \multicolumn{3}{|c|}{$T-1(N=19)$} & \multicolumn{3}{|c|}{ TO(N = 19) } & \multicolumn{3}{|c|}{$\mathrm{T1}(\mathrm{N}=19)$} & \multicolumn{3}{|c|}{$\mathrm{T} 2(\mathrm{~N}=16)$} \\
\hline & & $\begin{array}{l}\text { Mean } \pm \text { Std. } \\
\text { Dev. }\end{array}$ & Median & $\begin{array}{l}\text { Min; } \\
\text { Max }\end{array}$ & $\begin{array}{l}\text { Mean } \pm \text { Std. } \\
\text { Dev. }\end{array}$ & Median & $\begin{array}{l}\text { Min; } \\
\text { Max }\end{array}$ & $\begin{array}{l}\text { Mean } \pm \text { Std. } \\
\text { Dev. }\end{array}$ & Median & $\begin{array}{l}\text { Min; } \\
\text { Max }\end{array}$ & $\begin{array}{l}\text { Mean } \pm \text { Std. } \\
\text { Dev. }\end{array}$ & Median & $\begin{array}{l}\text { Min; } \\
\text { Max }\end{array}$ \\
\hline Fugl-Meyer Test $(n=18)$ & Upper Limb & $31.33 \pm 17.42$ & 33.5 & $5 ; 54$ & $31.21 \pm 16.92$ & 33 & $7 ; 55$ & $40.37 \pm 18.57$ & $49^{b}$ & $9 ; 62$ & $41.75 \pm 18.95$ & $49.5^{b}$ & $9 ; 63$ \\
\hline \multirow[t]{3}{*}{ Ashworth Scale $(n=18)$} & Shoulder & $0.67 \pm 0.77$ & 0.5 & $0 ; 2$ & $0.37 \pm 0.6$ & 0 & $0 ; 2$ & $0.16 \pm 0.37$ & 0 & $0 ; 1$ & $0.25 \pm 0.77$ & 0 & $0 ; 3$ \\
\hline & Elbow & $1.67 \pm 0.91$ & 1.5 & $0 ; 3$ & $1.79 \pm 0.98$ & 2 & $0 ; 3$ & $1.26 \pm 0.93$ & $1^{b}$ & $0 ; 3$ & $1.44 \pm 1.03$ & $1^{b}$ & $0 ; 3$ \\
\hline & Wrist & $0.89 \pm 1.02$ & 1 & $0 ; 4$ & $1 \pm 1$ & 1 & $0 ; 4$ & $0.68 \pm 0.67$ & 1 & $0 ; 2$ & $0.63 \pm 0.62$ & 1 & $0 ; 2$ \\
\hline $\operatorname{FIM}^{T M}(n=16)$ & Motor & $80.63 \pm 16.22$ & 82 & $53 ; 126$ & $82.26 \pm 13.88$ & $83^{\mathrm{a}}$ & $56 ; 126$ & $85.21 \pm 11.84$ & $86^{\mathrm{b}}$ & $69 ; 126$ & $85.94 \pm 6.32$ & $88.5^{b c}$, & $69 ; 91$ \\
\hline Visual Analogue Scale & Pain & & & & $22.05 \pm 26.33$ & 15 & $0 ; 80$ & $11.58 \pm 20.21$ & 0 & $0 ; 75$ & $0 \pm 0$ & ${ }_{0} b, c$ & $0 ; 0$ \\
\hline \multirow{10}{*}{$\begin{array}{l}\text { Medical Research Council, muscles' } \\
\text { strength criteria }\end{array}$} & Trapezius & & & & $3.37 \pm 0.76$ & 3 & $2 ; 5$ & $3.79 \pm 0.79$ & $4^{b}$ & $3 ; 5$ & $3.94 \pm 0.77$ & $4^{b}$ & $3 ; 5$ \\
\hline & Deltoid & & & & $3.68 \pm 0.58$ & 4 & $2 ; 4$ & $4.37 \pm 0.6$ & $4^{b}$ & $3 ; 5$ & $4.56 \pm 0.63$ & $5^{b}$ & $3 ; 5$ \\
\hline & $\begin{array}{l}\text { Pectoralis } \\
\text { Major }\end{array}$ & & & & $3.74 \pm 1.19$ & 4 & $0 ; 5$ & $4.47 \pm 0.77$ & $5^{b}$ & $2 ; 5$ & $4.75 \pm 0.45$ & $5^{\mathrm{b}}$ & $4 ; 5$ \\
\hline & $\begin{array}{l}\text { External } \\
\text { Rotatores }\end{array}$ & & & & $3.58 \pm 1.12$ & 4 & $0 ; 5$ & $4.11 \pm 1.15$ & $4^{b}$ & $0 ; 5$ & $4.25 \pm 1.29$ & $5^{b}$ & $0 ; 5$ \\
\hline & $\begin{array}{l}\text { Internal } \\
\text { Rotatores }\end{array}$ & & & & $32 \pm 1.57$ & 4 & $0 ; 4$ & $3.32 \pm 1.57$ & 4 & $0 ; 5$ & $3.56 \pm 1.46$ & 4 & $0 ; 5$ \\
\hline & Biceps Brachii & & & & $3.95 \pm 0.97$ & 4 & $2 ; 5$ & $4.53 \pm 0.61$ & $5^{b}$ & $3 ; 5$ & $4.81 \pm 0.4$ & $5^{b}$ & $4 ; 5$ \\
\hline & Triceps Brachii & & & & $3.74 \pm 1.28$ & 4 & $0 ; 5$ & $4.05 \pm 1.08$ & 4 & $1 ; 5$ & $4.31 \pm 1.14$ & $5^{b}$ & $1 ; 5$ \\
\hline & Flexor Carpi & & & & $340 ; 53$ & 4 & $0 ; 5$ & $3.32 \pm 1.67$ & 4 & $0 ; 5$ & $3.63 \pm 1.63$ & $4^{b}$ & $0 ; 5$ \\
\hline & Extensor Carpi & & & & $2.84 \pm 1.38$ & 3 & $0 ; 4$ & $3.21 \pm 1.51$ & 4 & $0 ; 5$ & $3.5 \pm 1.41$ & $4^{b}$ & $0 ; 5$ \\
\hline & $\begin{array}{l}\text { Latissimus } \\
\text { Dorsi }\end{array}$ & & & & $2.74 \pm 1.24$ & 3 & $0 ; 4$ & $3.47 \pm 1.12$ & $4^{b}$ & $1 ; 5$ & $3.94 \pm 1.06$ & $4^{b}$ & $1 ; 5$ \\
\hline Box \& Block Test & & & & & $11.89 \pm 11.69$ & 12 & $0 ; 38$ & $16.95 \pm 15.6$ & $17^{\mathrm{b}}$ & $0 ; 45$ & $17 \pm 15.9$ & $17^{b}$ & $0 ; 54$ \\
\hline FrenchayArm Test & & & & & $2.47 \pm 1.81$ & 3 & $0 ; 5$ & $3.26 \pm 2.05$ & $5^{\mathrm{b}}$ & $0 ; 5$ & $3.31 \pm 1.96$ & $4.5^{\mathrm{b}}$ & $0 ; 5$ \\
\hline Time Up and Go Test & & & & & $18.58 \pm 7.9$ & 17 & $10 ; 40$ & $17.47 \pm 8.55$ & $14^{\mathrm{b}}$ & $9 ; 38$ & $16.25 \pm 7.01$ & $15^{b}$ & $8 ; 34$ \\
\hline
\end{tabular}


indication of a clinical-functional improvement, thus a presumed effectiveness of the REOGo ${ }^{\mathrm{TM}}$ instrument [26,34-36]. In conclusion, further research with neuroimaging and/or TMS patterns, with an adequate control group, will be imperative to confirm these results.

\section{Additional material}

Additional file 1: Reo Go Protocol. The specific rehabilitation tasks. The assessment process is designed to view the patient's ability to perform specific exercises over time. The system is capable of measuring and displaying the patient's progress. The screen displays the activities of the patient on the machine, according to exercise dates. The following parameters can be changed: - Number of repetitions - how many times the exercise will be repeated . Speed - Values range between $10 \%$ and $200 \%$. The $100 \%$ value is 5 degrees per second. - Force (the resistance force of the joystick) - 3 possible values - High, Medium, and Low. Low force will require less force from user to initiate movement. Motion mode - Guided, Initiated, Step Initiated, Follow assist or Free • Scaling - Each exercise can be scaled according to patients' comfortable range of motion -i.e. stretched or squeezed from a center point. Values range from $0 \%$ to $200 \%$ of the original exercise. - Random - Each exercise can be run in Random mode, i.e. the computer selects the next point randomly from the points of the exercise. $2 \mathrm{D} / 3 \mathrm{D}$ mode - for every exercise, the radius of motion may be fixed (2D motion) or changeable (3D motion). The system provides the following exercise operating methods: - Guided mode - the patient is actively assisted by the system. - Initiated mode - the patient initiates each trajectory segment (between two successive recorded points) by himself, overcoming a predefined force threshold and then is actively assisted by the system for the rest of the segment - Step Initiated mode - similar to Initiated, but each trajectory segment (between two successive recorded points), is further divided to predefined "sub-segments" (3 degrees each) to overcome force threshold. - Follow Assist mode the handle moves at a slow speed towards the target. Once the user applies force to the handle in the specified direction the speed will be increased. Free mode - the patient actively leads the movement by himself. A summary of total training time is also displayed. Pressing the individual dates will display a summary of training for the specific date.

\section{Author details}

'Medicine Rehabilitation NOCSAE Hospital AUSL of Modena, Modena, Italy. ${ }^{2}$ IRCCS San Raffaele Pisana, Rome, Italy. ${ }^{3}$ Clinical and Molecular Epidemiology, IRCCS San Raffaele Pisana, Rome, Italy.

\section{Authors' contributions}

The overall design of the experiment was agreed upon by all authors. MF, PS and FB designed the overall study. FB, MF and PC defined the motor task. FB and PC selected the subjects and conducted all clinical evaluations. FB, PC and PS programmed the robot, including the Robot Training procedure, conducted all experiments and processed the data. VDA performed the statistical analysis. FB, PS, and VDA wrote the manuscript. All authors read and approved the manuscript.

\section{Competing interests}

The authors declare that they have no competing interests.

Received: 5 August 2010 Accepted: 9 April 2011 Published: 9 April 2011

\section{References}

1. WRITING GROUP MEMBERS, Lloyd-Jones D, Adams RJ, Brown TM, Carnethon M, Dai S, De Simone G, Ferguson TB, Ford E, Furie K, Gillespie C, Go A, Greenlund K, Haase N, Hailpern S, Ho PM, Howard V, Kissela B, Kittner S, Lackland D, Lisabeth L, Marelli A, McDermott MM, Meigs J, Mozaffarian D, Mussolino M, Nichol G, Roger VL, Rosamond W, Sacco R, Sorlie P, Roger VL, Thom T, Wasserthiel-Smoller S, Wong ND, Wylie-Rosett J,
American Heart Association Statistics Committee and Stroke Statistics Subcommittee: Heart disease and stroke statistics-2010 update: a report from the American Heart Association. Circulation 2010, 121(7):e46-e215, Epub 2009 Dec 17.

2. Kwakkel G, Kollen BJ, van der Grond J, Prevo AJH: Probability of regaining dexterity in the flaccid upper limb. Impact of severity of paresis and time since onset in acute stroke. Stroke 2003, 34:2181-86.

3. Kwakkel G, van Peppen R, Wagenaar RC, Wood Dauphinee S, Richards C, Ashburn A: Effects of augmented exercise therapy time after stroke. A meta-analysis. Stroke 2004, 35:2529-36.

4. Yavuzer G, Senel A, Atay MB, Stam HJ: "Playstation eyetoy games" improve upper extremity-related motor functioning in subacute stroke: a randomized controlled clinical trial. Eur J Phys Rehabil Med 2008, 44:237-44.

5. van Peppen RP, Kwakkel G, Wood-Dauphinee S, Hendriks HJ, van der Wees PJ, Dekker J: The impact of physical therapy on functional outcomes after stroke: what's the evidence? Clin Rehabil 2004, 18:833-62.

6. Huang VS, Krakauer JW: Robotic neurorehabilitation: a computational motor learning persective. J Neuroeng Neurorehab 2009, 6:5.

7. Krakauer JW: Motor learning: its relevance to stroke recovery and neurorehabilitation. Curr Opin Neurol 2006, 19:84-90

8. Mehrholz J, Platz T, Kugler J, Pohl M: Electromechanical and robot-assisted arm training for improving arm function and activities of daily living after stroke. Cochrane Database Syst Rev 2008, 4.

9. Kwakkel G, Kollen BJ, Krebs HI: Effects of robot-assisted therapy on upper limb recovery after stroke: a systematic review. Neurorehabil Neural Repair 2008, 22:111-21.

10. Prange GB, Jannik MJ, Groothuis-Oudshoorn CG, Hermens HJ, ljzerman MJ: Systematic review of the effect of robot-aided therapy on recovery of the hemiparetic arm after stroke. J Rehabil Res DEV 2006, 43:171-84.

11. Fugl-Meyer AR, Jääskö L, Leyman I, Olsson S, Steglind S: The post-stroke hemiplegic patient. 1. a method for evaluation of physical performance. Scand J Rehabil Med 1975, 7:13-31.

12. Lindmark B, Hamrin E: Evaluation of functional capacity after stroke as a basis for active intervention. Validation of a modified chart for motor capacity assessment. Scand J Rehabil Med 1988, 20:111-115.

13. Medical Research Council: Aids to the examination of the peripheral nervous system. London: Her Majesty's Stationery Office; 1976, Memorandum $n^{\circ} 45$.

14. Ashworth B: Preliminary trial of carisprodol in multiple sclerosis. Practitioner 1964, 192:540-2

15. Heller A, Wade DT, Wood VA, Sunderland A, Hewer RL, Ward E: Arm function after stroke: measurement and recovery over the first three months. J Neurol Neurosurg Psychiatry 1987, 50:714-719.

16. Mathiowetz V, Volland G, Kashman N, Weber K: Adult norms for the box and block test for manual dexterity. Am J Occup Ther 1985, 39:386-91.

17. Tesio L, Granger CV, Perucca L, Franchignoni FP, Battaglia MA, Russel CF: The FIM instrument in the United States and Italy: a comparative study. Am J Phys Med Rehabil 2002, 81:168-176.

18. Functional Indipendent Measure: versione italiana. Manuale d'uso. Ricerca Riabil; 1992:2(suppl):1-44.

19. Podsiadlo D, Richardson S: The timed "Up \& Go": a test of basic functional mobility for frail elderly persons. J Am Geriatr Soc 1991, 39:142-148.

20. Dorman PJ, Waddell F, Slattery J, Dennis M, Sandercock P: Is the Euroqol a valid measure of health-related quality of life after stroke? Stroke 1997, 28:1876-1882.

21. Franceschini M, La Porta F, Agosti M, Massucci M: Is health-related-quality oflife of stroke patients influenced by neurological impairments at one year after stroke? Eur J Phys Rehabil Med 2010.

22. Lo AC, Guarino PD, Richards LG, Haselkorn JK, Wittenberg GF, Federman DG, Ringer RJ, Wagner TH, Krebs HI, Volpe BT, Bever CT Jr, Bravata DM, Duncan PW, Corn BH, Maffucci AD, Nadeau SE, Conroy SS, Powell JM, Huang GD, Peduzzi P: Robot-assisted therapy for long-term upper-limb impairment after stroke. N Engl J Med 2010, 362(19):1772-83.

23. Casadio M, Giannoni P, Morasso P, Sanguineti V: A proof of concept study for the integration of robot therapy with physiotherapy in the treatment of stroke patients. Clin Rehabil 2009, 23:217-28.

24. Lauretani F, Saccavini M, Zaccaria B, Agosti M, Zampolini M, Franceschini M: Rehabilitation in patients affected by different types of stroke. A oneyear follow-up study. Eur J Phys Rehabil Med 2010. 
25. Bosecker C, Dipietro L, Volpe B, Krebs HI: Kinematic robot-based evaluation scales and clinical counterparts to measure upper limb motor performance in patients with chronic stroke. Neurorehabil Neural Repair 2010, 24(1):62-9.

26. Posteraro F, Mazzoleni S, Aliboni S, Cesqui B, Battaglia A, Dario P, Micera S: Robot-mediated therapy for paretic upper limbo $f$ chronic patients following neurological injury. J Rehabil Med 2009, 41:976-80.

27. Staubli Patricia, Tobias Nef, Verena Klamroth-Marganska, Robert Riener: Effects of intensive arm training with the rehabilitation robot ARMin II in chronic stroke patients: four single-cases. Journal of NeuroEngineering and Rehabilitation 2009, 6:46.

28. Kluzik J, Diedrichsen J, Shadmehr R, Bastian AJ: Reach adaptation: what determines whether we learn an internal model of the tool or adapt the model of our arm? J Neuropysiol 2008, 100:1455-64.

29. Esquenazi A, Mayer N, Garreta R: Influence of botulinum toxin type A treatment of elbow flexor spasticity on hemiparetic gait. Am J Phys Med Rehabil 2008, 87:305-11.

30. Volpe BT, Krebs HI, Hogan N: A novel approach to stroke rehabilitation: robot-aided sensorimotor stimulation. Neurology 2000, 54:1938-44.

31. Masiero S, Celia A, Rosati G, Armani M: Robotic-assisted rehabilitation of the upper limb after acute stroke. Arch Phys Med Rehabil 2007, 88:142-9.

32. Rabadi MH, Galgano M, Lynch D, Akerman M, Lesser M, Volpe BT: A pilot study of activity-based therapy in the arm motor recovery post stroke: a randomized controlled trial. Clin Rehabil 2008, 22:1071-82.

33. Treger I, Faran S, Ring H: Robot-assisted therapy for neuromuscular training of subacute stroke patients. A feasibility study. Eur $j$ Phys Rehabil Med 2008, 44:431-5.

34. Volpe BT, Lynch D, Rykman-Berland A, Ferraro M, Galgano M, Hogan N, Krebs HI: Intensive sensorimotor arm training mediated by therapist or robot improves hemiparesis in patients with chronic stroke. Neurorehabil Neural Repair 2008, 22:305-10.

35. Bovolenta F, Goldoni M, Clerici P, Agosti M, Franceschini M: Robot therapy for functional recovery of the upper limbs: a pilot study on patients after stroke. J Rehabil Med 2009, 41:971-75.

36. Ferraro M, Palazzolo JJ, Krol J, Krebs HI, Hogan N, Volpe BT: Robot-aided sensorimotor arm training improve outcome in patients with chronic stroke. Neuroreahbil Neural Repair 2008, 22:305-10.

doi:10.1186/1743-0003-8-18

Cite this article as: Bovolenta et al:: Robot-aided therapy for upper limbs in patients with stroke-related lesions. Brief report of a clinical experience. Journal of NeuroEngineering and Rehabilitation 2011 8:18.

\section{Submit your next manuscript to BioMed Central and take full advantage of:}

- Convenient online submission

- Thorough peer review

- No space constraints or color figure charges

- Immediate publication on acceptance

- Inclusion in PubMed, CAS, Scopus and Google Scholar

- Research which is freely available for redistribution

Submit your manuscript at www.biomedcentral.com/submit
C Biomed Central 